\title{
Study of a High-risk Group of Stage 2 Colon Cancer
}

\author{
Dr. S. R. Kulkarni ${ }^{1}$, Dr. Jigneshkumar K. Savsaviya ${ }^{2}$ \\ ${ }^{1}$ Professor, Department of Surgery, Krishna Hospital, Karad, Maharashtra, India \\ ${ }^{2}$ Resident, Department of Surgery, Krishna Hospital, Karad, Maharashtra, India
}

\begin{abstract}
Aim: Adjuvant therapy is not routinely recommended in stage II colon cancer, but may be considered for high-risk patients. Our aim is to identify clinicopathologic characteristics in colon cancer stage II, which are associated with an increased risk of tumour recurrence and tumour-related death. Objective and Methods: For evaluating recurrence factors in Stage II colon adenocarcinoma, a clinical, non-experimental, longitudinal and retrospective study was done in the Department of surgery in Krishna hospital, karad from june2005 to June 2015. Results: In 200 eligible patients 20 (10\%) recurrence cases were observed that appeared in an average 2.3 years after surgery. The main site of recurrence was local-regional (5.5\%), pulmonary (2.5\%), hepatic (1\%), and peritoneal (1\%). The following factors were considered: age, sex, CEA level, type of operation (elective or emergency), site of the primary injury, invasion (T3 or T4), lymphatic vessel invasion, histologic differentiation, and synchronous carcinoma. We found that patients more than 70 years old $(p=0.0305)$ have a lesser disease-free time. Be more than 70 years old was the only recurrencerelated factor; this group has 2.56 times more risk of recurrence. No other studied variable was related to recurrence.
\end{abstract}

Keywords: Colon, Adenocarcinoma, Risk factors, Recurrence

\section{Introduction}

Colorectal cancer is development of cancer in the colon or rectum. ${ }^{1}$ It is due to abnormal growth of cells that have ability to invade or spread to other parts of body. ${ }^{2}$ Globally , colorectal cancer is the third most common type of cancer making up about $10 \%$ of all cases.In 2012 there were 1.4 million new cases and 694,000 deaths from the disease.It is more common in developed countries, where more than $65 \%$ of cases are found.

Colorectal cancer 5-year survival rate is $80 \%$ to $90 \%$ for disease located in the intestinal wall, $40 \%$ to $60 \%$ for regional disease, and is less than $5 \%$ for metastatic disease. From all patients with colon cancer, the incidence of Stage II is from $40 \%$ to $45 \%$; and $80 \%$ of patients with Stage II cancer colon are disease free after five years, admitted for surgical treatment with curative intention (standard treatment) and about 20\% develop recurrence within the first five years. $^{4}$

Standard treatment for Stage II colon cancer is surgery with no adjuvant therapy; chemotherapy as adjuvant therapy is still controversial for clinical stage II but some series recommend complementary chemotherapy for patients with clinical pathological prognostic factors of recurrence. ${ }^{5}$

In Stage III, chemotherapy as adjuvant treatment to surgery improved survival. ${ }^{6}$ No remarkable additional benefit was observed in studies about Stage II, or Dukes B, colon cancer treated by surgery and adjuvant chemotherapy in relation to those treated only surgically. ${ }^{6-7}$ With the purpose of identifying what patients have greater risk of recurrence in Stage II colon cancer, clinical-pathological prognostic factors are evaluated that can predict recurrence ${ }^{8-12}$ which could benefit from adjuvant chemotherapy. ${ }^{6-7}$

\section{Patients and Methods}

We conducted a non-experimental, longitudinal and retrospective clinical study of all patients admitted to curative resection of stage II colon adenocarcinoma, with surgery performed in Krishna hospital, karad from JUNE 2005 to JUNE 2015.

Inclusion criteria were: 1) colon adenocarcinoma. 2) stage II, pT3 or pT4 with negative ganglia and without distant metastasis. 3) no residual disease or compromised edges. 4) no adjuvant chemotherapy.

Exclusion criteria were: 1) patients operated in other hospital or institutions. 2) patients submitted to non-curative surgery. For evaluating recurrence, follow-up time was from the day of the operation to the last follow up.

The studied sample is formed by 207 patients Stage IIa and IIb, admitted to curative resection for colon adenocarcinoma. Seven patients were excluded (3.4\%) with non-curative surgery. Finally 200 patients were selected for inclusion criteria.

The present study uses Krishna hospital databases, where are registered all patients treated for colon adenocarcinoma in the period of study. This information was complemented by the following variables: date of recurrence, site of recurrence and date of death. A follow-up work was done to reduce the number of patients lost, by means of location by the telephone, and life verification with the registers all living people.

One used the Chi-square test to establish the association between studied factors and recurrence, recurrence ratio was calculated by Kaplan - Meier method and Cox multivariate analysis was used for selecting prognostic factors for recurrence.

\section{Results}

\section{Location of recurrence in Stage II colon cancer}

Recurrence developed in 20 (10\%) of the 200 eligible patients. The mean time for recurrence was 2.3 years after 


\section{International Journal of Science and Research (IJSR) \\ ISSN (Online): 2319-7064 \\ Index Copernicus Value (2013): 6.14 | Impact Factor (2015): 6.391}

surgery with curative intention, with a time interval from 2.5 months to 8.5 years. Eleven patients (5.5\%) had localregional recurrence from 5 months to 6.7 years, and a mean time of recurrence of 2.4 years; among them six patients (3\%) had local recurrence at the surgical table from 8 months to 4.6 years, and a mean time of recurrence of 2.3 years; and three patients (1.5\%) had local recurrence in the anastomosis from 5 months to 6.7 years, and an average time of recurrence of 6.4 months. Five patients (2.5\%) had pulmonary recurrence from 1 to 8.5 years, with a mean time of recurrence of 2.6 years. Two patients (1\%) had hepatic recurrence in a 7- to 20-month interval, with a mean time of 14 months. Two patients (1\%) had peritoneal recurrence from 2.5 months to 6.5 months, with a mean time of recurrence of 4.6 months (Table 1 ).

Table 1: Recurrence in 200 Stage II Colon Cancer

\begin{tabular}{|c|c|c|c|c|}
\multicolumn{5}{c}{ patients } \\
\hline Recurrence & $\mathbf{N}$ & $\%$ & Time & Mean \\
\hline Local-regional & 11 & 5.5 & $5 \mathrm{~m}-6.7 \mathrm{y}$ & $2.4 \mathrm{y}$ \\
\hline Pulmonary & 5 & 2.5 & $1 \mathrm{y}-8.5 \mathrm{y}$ & $2.6 \mathrm{y}$ \\
\hline Hepatic & 2 & 1.0 & $7 \mathrm{~m}-20 \mathrm{~m}$ & $14 \mathrm{~m}$ \\
\hline Peritoneal & 2 & 1.0 & $2.5 \mathrm{~m}-6.5 \mathrm{~m}$ & $4.6 \mathrm{~m}$ \\
\hline $\begin{array}{c}\text { m = month } \\
\text { y = year }\end{array}$ & & & \\
\hline
\end{tabular}

Time of recurrence and factors associated to recurrence in Stage IIA and IIB colon adenocarcinoma

The disease-free mean time was 10.91 years, with a SD 0.35 CI 95\% 10.22 - 11.60. The ratio of patients with recurrence in five years was estimated in 0.1257 , with a standard deviation of 0.0294 . The last case of recurrence occurred 8.55 years after diagnosis and the ratio of patients with recurrence is considered at that moment in 0.1878. (Figure 1). Age did not have a significant association with the recurrence $(p=0.096)$ (Table 2$)$.

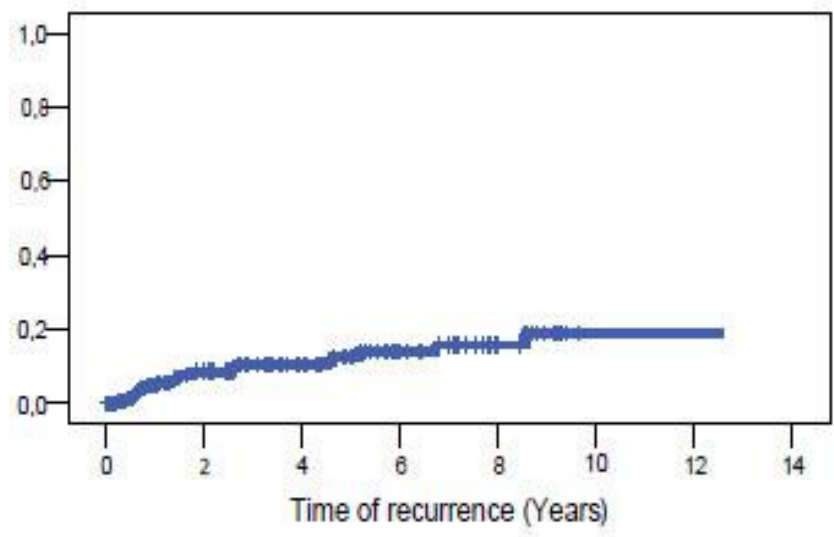

Figure 1: Recurrence in 200 patients with Stage II colon cancer.
Table 2: Univariate analysis of 20 cases of recurrence

\begin{tabular}{|c|c|c|c|c|}
\hline Variable & $N$ & Recurrence (N) & Recurrence (\%) & $p$ \\
\hline \multicolumn{5}{|c|}{ Age } \\
\hline$>70$ years & 58 & 9 & 45 & 0.096 \\
\hline \multicolumn{5}{|c|}{ Sex } \\
\hline Male & 87 & 10 & 50 & \multirow{2}{*}{0.537} \\
\hline Female & 87 & 10 & 50 & \\
\hline \multicolumn{5}{|c|}{ CEA } \\
\hline High & 36 & 4 & 40 & 0.801 \\
\hline \multicolumn{5}{|c|}{ Type of operation } \\
\hline Elective & 185 & 15 & 20 & \multirow{2}{*}{0.179} \\
\hline Emergency & 15 & & & \\
\hline \multicolumn{5}{|c|}{ Intestinal Obstruction } \\
\hline Yes & 12 & & & \\
\hline \multicolumn{5}{|c|}{ Site } \\
\hline Unknown & 18 & & & \\
\hline Ascendent colon & 59 & 8 & 40 & 0.278 \\
\hline Hepatic flexure & 23 & 2 & 10 & 0.625 \\
\hline Transverse colon & 26 & 2 & 10 & 0.674 \\
\hline Splenic flexure & 6 & 0 & 0 & \\
\hline Descendent colon & 15 & 1 & 5 & 0.655 \\
\hline Sigmoid & 62 & 7 & 35 & 0.683 \\
\hline \multicolumn{5}{|c|}{ Invasion } \\
\hline T3/Stage IIA & 170 & 17 & 85 & \multirow{2}{*}{1} \\
\hline T4/Stage IIB & 30 & 3 & 15 & \\
\hline Lymphatic vessels & 18 & 3 & 15 & 0.323 \\
\hline Venous invasion & 4 & 1 & 5 & 0.312 \\
\hline \multicolumn{5}{|c|}{ Classification } \\
\hline Differentiated & 177 & 16 & 80 & 0.209 \\
\hline Undifferentiated & 23 & 4 & 20 & 0.7 \\
\hline \multicolumn{5}{|c|}{ Synchonic Tumor } \\
\hline Yes & 7 & 1 & 5 & 0.7 \\
\hline
\end{tabular}

\section{Prognostic factors}

Results show patients more than 70 years old have a significantly shorter disease-free time $(\mathrm{p}=0.0305)$ (Figure 2). No other factor turned out to be significant (Table 3). Cox regression showed that patients more than 70 years old have 2.56 times more risk of recurrence (Table 4), that is, be more than 70 years is a factor determining recurrence.

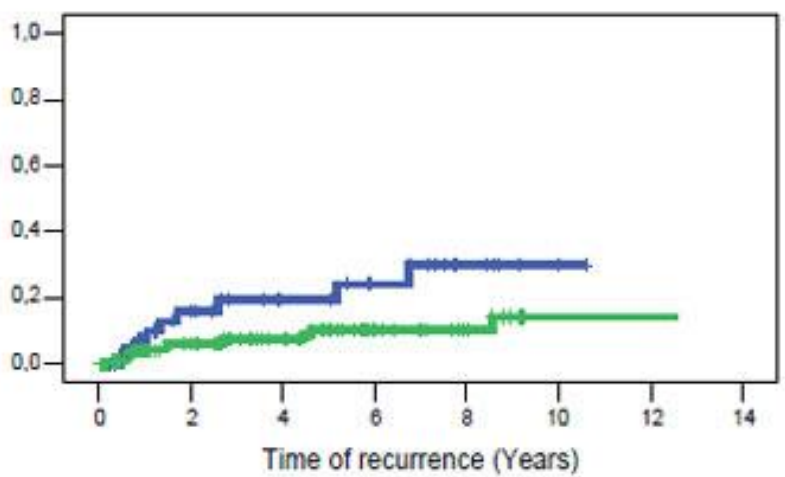

Figure 2: Recurrence according to age (blue line - younger than 70 years; green line - 70 years or older). 


\section{International Journal of Science and Research (IJSR) \\ ISSN (Online): 2319-7064}

Index Copernicus Value (2013): 6.14 | Impact Factor (2015): 6.391

Table 3 - Kaplan - Meier analysis in 20 cases of recurrence

\begin{tabular}{|c|c|c|c|c|c|}
\hline Variable & $\begin{array}{c}\text { Disease-free } \\
\text { time }\end{array}$ & $\begin{array}{c}\text { Standard } \\
\text { Deviation }\end{array}$ & CI 95\% & $\begin{array}{c}\text { Log Rank } \\
\text { Test }\end{array}$ & $p$ \\
\hline \multicolumn{6}{|c|}{ Age } \\
\hline$<70$ years & 8.31 & 0.66 & $7.01-9.61$ & \multirow{2}{*}{4.68} & \multirow{2}{*}{0.0305} \\
\hline$>70$ years & 11.36 & 0.36 & 10.66-12.06 & & \\
\hline \multicolumn{6}{|c|}{ Sex } \\
\hline Male & 9.71 & 0.45 & $8.83-10.59$ & \multirow{2}{*}{0.09} & \multirow{2}{*}{0.7612} \\
\hline Female & 11.09 & 0.45 & 10.21-11.97 & & \\
\hline \multicolumn{6}{|c|}{ CEA } \\
\hline High & 8.51 & 0.54 & $7.44-9.57$ & 0.17 & 0.6791 \\
\hline \multicolumn{6}{|c|}{ Type of surgery } \\
\hline Elective & 10.38 & 0.35 & 9.69-11.07 & 1.55 & 0.2136 \\
\hline \multicolumn{6}{|c|}{ Site } \\
\hline \multicolumn{6}{|l|}{ Unknown } \\
\hline Ascendent colon & 9.85 & 0.71 & $8.47-11.23$ & 1.37 & 0.2426 \\
\hline Hepatic flexure & 9.46 & 0.76 & $7.97-10.95$ & 0.08 & 0.7748 \\
\hline Descendent colon & 9.85 & 0.89 & $8.12-11.59$ & 0.27 & 0.6046 \\
\hline Sigmoid & 10.58 & 0.7 & $9.21-11.96$ & 0.47 & 0.4918 \\
\hline \multicolumn{6}{|c|}{ Invasion } \\
\hline T3/Stage II A & 10.87 & 0.39 & 10.11-11.63 & \multirow{2}{*}{0} & \multirow{2}{*}{0.967} \\
\hline T4/Stage II B & 8.64 & 0.56 & $7.55-9.73$ & & \\
\hline Lymphatic vessels & 5.35 & 0.8 & $3.78-6.92$ & 2.81 & 0.0934 \\
\hline Venous invasion & 2.38 & 0.27 & $1.85-2.91$ & 1.69 & 0.1941 \\
\hline \multicolumn{6}{|c|}{ Classification } \\
\hline Differentiated & 11.08 & 0.36 & 10.38-11.78 & \multirow{2}{*}{2.1} & \multirow{2}{*}{0.1471} \\
\hline Undifferentiated & 9.04 & 1.26 & 6.57-11.51 & & \\
\hline \multicolumn{6}{|c|}{ Synchonic Tumor } \\
\hline Yes & 7.22 & 1.89 & 3.52-10.93 & 0.58 & 0.4466 \\
\hline
\end{tabular}

Table 4: Recurrence-related variable according to Cox multivariate analysis

\begin{tabular}{|l|c|c|c|c|c|}
\hline Category & $S D$ & Wald & $p$ & $R R$ & CI95\% \\
\hline Age \\
\hline$>70$ yrs & 0.45 & 4.35 & 0.0370 & 2.55 & $1.06-6.19$ \\
\hline
\end{tabular}

\section{Discussion}

World literature have few studies on risk factors for recurrence in Stage II colon cancer, and some take into consideration clinical findings such as type of presentation by emergency, be it by obstruction or perforation, site, CEA etc. and others consider pathological results such as histologic type, depth, differentiation, vascular and lymphatic invasion, etc. ${ }^{8,10,12,14-15}$ demonstrating in some cases a certain relation with recurrence where a benefit would be gained from adjuvant treatment. ${ }^{6-7}$

In this study no evaluated factor had relation with this event, except age: patients more than 70 years old had a greater risk of recurrence, up to 2.56 times. In no study here mentioned was age a recurrence prognostic factor, and one would have to individualize patients according to their general clinical condition and comorbidity, analyzed the disadvantages and limitations of adjuvant treatment, since in our society average life expectancy is less than 70 years.

The incidence of Stage II colon cancer was compatible with world rates, around $40 \%$, and recurrence percentage was $10 \%$, half of the reported world average. ${ }^{4}$ Nevertheless, around $30 \%$ of cases did not have the minimum follow-up time of two years; if we excluded patients about whom there is no certainty on their being disease free, the recurrence rate would rise to $15 \%$.

In spite of the recommendations of ASCO, namely to consider the possibility of using adjuvant chemotherapy for patients who have as pathology results T4, lymphatic, vascular, or neural invasion, or else are operated due to perforation, less than 13 resected lymph nodes, this study demonstrated no statistical significance of these variables as regards recurrence.

Our study demonstrated that the most important prognostic factor for colon cancer is the presence of lymph nodes affected by the disease and that the main distant recurrences are the hepatic and the pulmonary one, but for patients with colon cancer without lymphnodes (Stage II), one has not data for pointing out the most important prognostic factors, and our study showed a local-regional recurrence rate of $5.5 \%$ from the $10 \%$ cases, and thus surgery plays for these patients a very important role. ${ }^{18}$

Due to the great heterogeneity of Stage II colon tumors, the role of adjuvant chemotherapy is very controversial, since patient with tumors of the same clinical stage present different results, mainly related to recurrence. This way, the standard procedure is unable to exactly predict this neoplasia prognosis and makes necessary the identification of specific molecular characteristics of each tumor that can predict a better response to chemotherapy, intending to significantly reduce recurrence rates in Stage II. For identifying the groups of patients who can need adjuvant treatment, the correlation of molecular analysis and clinical data would be very helpful. 


\section{International Journal of Science and Research (IJSR) \\ ISSN (Online): 2319-7064 \\ Index Copernicus Value (2013): 6.14 | Impact Factor (2015): 6.391}

The course of colon cancer, many genetic changes accumulate that frequently cause a kind of genomic instability. The two better known mechanisms of genomic instability are chromosomal instability (CIN) and microsatellite instability (MSI). CIN phenotype is found in about $85 \%$ of sporadic tumors and is characterized by aneuploidies, manifold chromosomal rearrangements and the accumulation of somatic mutations in K-RAS oncogene and in tumor-suppressor genes TP53 and APC. ${ }^{16-18}$ MSI phenotype is associated with small insertions and deletions, mainly in repetitive sequences (microsatellite), and is found in approximately $15 \%$ of the cases. MSI is caused by defects in DNA repair system, including repair errors during DNA replication.

This instability is related to patients' prognosis and response to chemotherapy, ${ }^{19}$ being frequently referred as highfrequency MSI (MSI-H). Diverse theories were postulated to explain why tumors with MSI-H present a better prognosis in spite of unfavorable histologic characteristics. One theory suggests that accumulation of genetic abnormalities causes aberrant protein expression, recognized by the immune system and triggering the destruction of tumor-like cells. Another theory relates the defect of the repair system to a better survival, since several mutations are not repaired during the replication and their accumulation becomes incompatible with cellular life.

Mutations in TP53 gene are associated to tumors aggressive growth and to reduced survival rates, whereas MSI-H seems to be related to a favorable prognosis of the disease. ${ }^{16}$ Associations between somatic genetic alterations and the clinical behavior of colorectal tumors are rare.

Recent studies associated to tight-junction proteins key molecular components in cellular proliferation and neoplastic signaling, due to their double function of intracellular-extracellular signaling and cytoskeleton. Therefore, neoplastic cells show structural and functional deficiencies in "tight junction". Claudina-1, one of the proteins that comprise "tight junction", has a low expression in Stage II colorectal cancer and is a strong indicator of recurrence and poor survival for Stage II patients. ${ }^{20}$

Another cellular-adhesion molecules involved in the progression of colorectal cancer is E-cadherin, which would help to identify sub-groups of high-risk patients which can need an appropriate and continuous therapeutic strategy. ${ }^{21}$

Although this study intends to avoid adjuvant treatment for Stage II colon cancer patients submitted to surgical treatment with curative intention (an adequate oncologic operation), it is crucial to understand that colorectal cancer is a multiple-route disease that includes/understands clinical, pathological characteristics and molecular individuals and that the present idea of carcinogenesis routes simplification has been the main process negatively affecting the identification of risk factors for colorectal cancer. ${ }^{22}$

Based on these molecular antecedents, the immunohistochemical study of TP53, K-RAS and APC, as well as the analysis of microsatellite instability and the sequencing of these genes in patients with Stage II colorectal cancer is suggested. ${ }^{23,24}$

\section{Conclusions}

Five-year recurrence of patients curatively operated for Stage II colon adenocarcinoma in krishna hospital , karad from june 2005 to june 2015 has been 0.1257 with a standard deviation of 0.0294 .

The only factor related to recurrence has been age: patients with more than 70 years at the time of the main surgery ( $p=$ 0.0305 ), had a risk of recurrence 2.56 times greater. No other studied factor has relation to recurrence. It is suggested molecular profile should be performed in stage II colon cancer patients.

\section{References}

[1] Colon cancer treatment. NCI.2014-05-12. Retrived 29 june 2014.

[2] Defining cancer .national cancer institute. retrived 10june 2014

[3] world cancer report 2014. World health organization. 2014. Pp. chapter 1.1. isbn 9283204298.

[4] Shepherd NA, Baxter KJ, Love SB. The prognostic importance of peritoneal involvement in colonic cancer: a prospective evaluation. Gastroenterology 1997;112:1096-102.

[5] Zanibioni A, Labianca R. GrupoItaliano per lo Studio e la curadeitumorideldigerente: adjuvant therapy for stage II colon cancer: an elephant in the living room? Ann Oncol 2004;15:1310-8.

[6] Mamounas EP, Wieand S, Wolmark N, Bear HD, Atkins JN, Song K, et al. Comparative efficacy of adjuvant chemotherapy in patients with Dukes' B versus Dukes' C colon cancer: results from four National Surgical Adjuvant Breast and Bowel Project Adjuvant Studies (C-01, C-02, C-03, and C-04). J ClinOncol 1999; 17:349-55.

[7] By the International Multicentre Pooled Analysis of B2 Colon Cancer Trials (IMPACT B2) Investigators. efficacy of adyuvantfluoracil and folinic acid in B2 colon cancer. J ClinOncol 1999;17:1356-63.

[8] Merkel S, Wein A, Gunter K, Papadopoulos T, Hohenberger W, Hermanek P. High-risk groups of patients with Stage II colon carcinoma. Cancer 2001;92:1435-43.

[9] Ojuyama.T; Nakamura.T; Yamaguchi.M. Budding is useful to select high-risk patients in stage II welldifferentiated or moderately differentiated colon carcinoma. Dis Colon Rectum 2003;46:1400-6.

[10] Tanaka M, Hashiguchi Y, Ueno H, Hase K, Michizuki $\mathrm{H}$. Tumor budding at invasive margin can predict patients at high risk of recurrence after curative surgery for stage ii, t3 colon cancer. Dis Colon Rectum 2003;46:1054-9.

[11]Cascinu S, Georgoulias V, Kerr D, Maughan T, Labianca R, Ychou M. Colorectal cancer in the adjuvant setting: perspectives on the treatment and role of prognostic factors. Ann Oncol 2003;14Suppl 2:ii25-9.

[12] Petersen VC; Baxter KJ; Love SB; Sheperd NA. Identification of objective pathological prognostic 


\section{International Journal of Science and Research (IJSR) \\ ISSN (Online): 2319-7064}

Index Copernicus Value (2013): 6.14 | Impact Factor (2015): 6.391

determinants and models of prognosis in Dukes B Colon Cancer. Gut 2002;51:65-9.

[13] Greene FL, Page DL, Fleming ID, Balch CM, Haller DG, Morrow M. AJCC: Manual de estadiamento do cancer.6th ed. Trad. De D D Rosa. Porto Alegre: Artmed; 2004. Cólon e reto; p.129-38.

[14] Burdy G, Panis Y, Alves A, Nemeth J, Lavergne-Slove A, Valleur P. Identifying patients with T3-T4 nopde negative colon cancer at high risk of recurrence. Dis Colon Rectum 2001;44:1682-88.

[15] Harris GJ, Church JM, Senagore AJ, Lavery IC, Hull TL,Strong SA, et al. Factors affecting local recurrence of colonic adenocarcinoma. Dis Colon Rectum 2002;45:1029-34.

[16] Westra JL, Plukker JT, Buys CH, Hofstra RM. Genetic alterations in locally advanced stage II/III colon cancer: a search for prognostic markers. Clin Colorectal Cancer 2004;4:252-9.

[17] Chang SC, Lin JK, Yang SH, Wang HS, Li AF, Chi CW. Relationship between genetic alterations and prognosis in sporadic cancer colorectal cancer. Int J Cancer 2006;118:1721-7.

[18] Akkiprik M, Ataizi-Celikel C, Dusunceli F, Sonmez O, Gulluodlu BM, Sav A, et al. Clinical significance of p53, K-ras and DCC genes alterations in the stage I-II colorectal cancers. J Gastrointest Liver Dis 2007;16:117.

[19] Kruhoffer M, Jensen JL, Laiho P, et al. Gene expression signatures for colorectal cancer microsatellite status and HNPCC. Br J Cancer 2005;92:2240-8.

[20] Resnick MB, Konkin T, Routhier J, Sabo E, Pricovolo VE. Claudin-1 is a storng prognostic indicator in stage II colonic cancer: a tissue microarray study. Mod Pathol 2005;18:511-8.

[21] Ikeda M, Sekimoto M, Monden M. Ngan CY, Yamamoto H, Seshimo I et al. A multivariate analysis of adhesion molecules expression in assessment of colorectal cancer. J SurgOncol 2007;95:652-62.

[22] Jass JR. Classification of colorectal cancer base don correlation of clinical, morphological and molecular features. Histopathology 2007;50:113-30.

[23] Carethers JM, Smith EJ, Behling CA, Nguyen L, Tajima A, Doctolero RT, et al. Use of 5-fluorouracil and survival in patients with microsatellite-unstable colorectal cancer. Gastroenterology 2004;126:394-401.

[24]Ribic CM, Sargent DJ, Moore MJ, Thibodeau SN, French AJ, Goldberg RM, et al. Tumor microsatelliteinstability status as a predictor of benefit from fluorouracil-based adjuvant chemotherapy for colon cancer. N Engl J Med 2003;349:247-57. 